\title{
Dielectric Relaxation in a Styrene-Acrylonitrile Co- polymer During and After its Polymerization ${ }^{1,2}$
}

\author{
Paul Ehrlich ${ }^{3}$ and Nicholas J. De Lollis
}

\begin{abstract}
Dielectric relaxation in plasticized copolymers of styrene and acrylonitrile is studied during their formation as well as in the fully polymerized copolymers by measurements of dielectric constant and loss factor at several frequencies from $100 \mathrm{c} / \mathrm{s}$ to $100 \mathrm{kc} / \mathrm{s}$. In the polymerizing mixture, there occur, at an early stage of the reaction, sigmoid decreases in the dielectric constant at each frequency, accompanied by maxima in the loss factor, when these variables are plotted as a function of reaction time. These changes are interpreted as resulting from the relaxation of the nitrile groups. The electrical properties of the fully polymerized copolymer, as it goes through its glass transition, are in semiquantitative agreement with those of the polymerizing mixture at the stage of the reaction referred to, demonstrating the occurrence of similar phenomena in each case.
\end{abstract}

\section{Introduction}

Only isolated studies on the variation of electrical properties throughout a polymerization reaction have been reported. Lazarev and Raschketaev [1] ${ }^{4}$ have noted a dependence of d-c conductivity, dielectric constant, and dielectric loss on the degree of polymerization of the product resulting from the heat treatment of drying oils. Majury and Melville [2] have drawn certain conclusions about the nonstationary state in vinyl-type polymerizations from the observation of very small and very rapidly occurring changes in dielectric constant observed in the early stages of the reaction. This paper reports on a direct study of changes in dielectric constant and dielectric loss occurring throughout the polymerization of a polar casting resin. The measurements were carried out while the reaction mixture was polymerizing and cross-linking from a viscous solution containing mostly monomer to the fully cured polymer, which was a hard solid.

According to the Debye concept of dipolar relaxation [3] the contribution of dipole relaxation to the dielectric constant, $\epsilon^{\prime}(\omega)-\epsilon_{\infty}$, is given by

$$
\boldsymbol{\epsilon}^{\prime}(\omega)-\boldsymbol{\epsilon}_{\infty}=\left(\boldsymbol{\epsilon}_{s}-\boldsymbol{\epsilon}_{\infty}\right) / 1+\omega^{2} \tau^{2},
$$

and the loss factor, $\epsilon^{\prime \prime}$, resulting from this process is given by

$$
\epsilon^{\prime \prime}(\omega)=\left(\epsilon_{s}-\epsilon_{\infty}\right) \omega \tau / 1+\omega^{2} \tau^{2} .
$$

The loss factor thus goes through a maximum at a frequency $f_{\max }$, such that

$$
\tau=1 / 2 \pi f_{\max } .
$$

Furthermore, the Debye theory predicts for a dilute suspension of dipolar spheres in a nonpolar solvent

1 Sponsored by the Department of the Army, Office of the Chief of Ordnance. ${ }^{2}$ Presented in part before the American Physical Society, Durham, N. C., March 26-28, 1953.

${ }_{3}$ Present address, Department of Chemistry, Harvard University, Cambridge, Mass.

${ }^{4}$ Figures in brackets indicate the literature references at the end of this paper. that

$$
\tau=4 \pi \eta a^{3} / k T
$$

where $\epsilon_{s}$ and $\epsilon_{\infty}$ are the static and infinite frequency values of the dielectric constant, respectively, $\epsilon^{\prime}(\omega)$ is the frequency dependent value of the dielectric constant, $\epsilon^{\prime \prime}(\omega)$ is the loss factor $\left(\epsilon^{\prime \prime}=\epsilon^{\prime}\right.$ $\tan \delta), \tan \delta$ is the loss angle tangent or dissipation factor, $f$ is the frequency in cycles per second, $\omega=2 \pi f, \tau$ is the relaxation time for dipole relaxation, $\eta$ is the viscosity, $a$ is the radius of the spheres, $k$ is the Boltzmann constant, and $T$ the absolute temperature.

Relation (2) has generally been found invalid, because in most systems investigated, values of the viscosity calculated from it differed from those observed, sometimes by orders of magnitude. The quantity $\eta$ has therefore often been represented as an "internal viscosity," a concept lacking quantitative definition in terms of measurable variables. In alternate treatments, applicable to systems with sharply specified energy states [4], the hydrodynamic theory is abandoned and a thermodynamic one is substituted.

In the case at hand, it will be found useful to retain the hydrodynamic concept in a qualitative sense. This predicts a dependence of the relaxation time, and, therefore, of the frequency region in which dipolar losses occur, on viscosity and temperature. The usual way of studying the effect of these variables is, of course, by determining the effect of temperature on the dielectric properties of the solid polymer [5]. The hydrodynamic concept, however, suggests that similar effects might be observed by changing the viscosity at constant temperature. This picture, as we shall see, does indeed furnish a qualitative interpretation of the dielectric changes occurring during the polymerization reaction. In fact, the agreement between corresponding changes occurring in the fully polymerized polymer as a function of temperature and those occurring in the polymerizing mixture as a function of reaction time will be seen to be semiquantitative. 


\section{Materials and Methods}

\subsection{Materials}

The primary ingredients of the casting resin were commercial grades of styrene, polystyrene, divinylbenzene, and hydrogenated terphenyl plasticizer. Of these the sytrene and the plasticizer were used without further purification, whereas the acrylonitrile (AN) was redistilled once, removing most, but not all, of the inhibitor. To insure a reasonable shelf life and a good curing rate of the stock solution, the composition of which will be described presently, the polystyrene used was a 50-50 mixture of polymers with weight-average-molecular weights of 160,000 (manufacturer's data) and 840,000 , as determined by light-scattering measurements. The divinylbenzene preparation (DVB) was stated by the manufacturer to contain 40 percent of divinylbenzene, most of which was the meta isomer. The other ingredients in this product were mainly diethylbenzene and ethyl vinylbenzene. The inhibitor was removed from it by passing it through activated alumina.

The minor ingredients of the resin were purified commercial benzoyl peroxide, a cobalt catalyst (cobalt naphthenate) containing 6 percent of cobalt, which was used without further purification and Promoter A. ${ }^{5}$

\subsection{Methods}

The systems studied, except the ones containing no DVB, were made up from a stock solution of the following composition by weight: Styrene, 50 parts; polystyrene, 30 parts; hydrogenated terphenyl, 13 parts; AN, 5 parts; DVB solution, 2 parts. ${ }^{6}$ Systems termed 6-percent and 11-percent DVB were made up by adding $4 \mathrm{~g}$ and $10 \mathrm{~g}$ of the DVB solution, respectively, to $100 \mathrm{~g}$ of the stock solution; the system with the nominal $\mathrm{AN}$ content of 10 percent was made up by adding an additional $5 \mathrm{~g}$ of $\mathrm{AN}$ to $100 \mathrm{~g}$ of the stock solution. The system termed 0 -percent DVB was made up separately and differed from the stock solution in that the $2 \mathrm{~g}$ of DVB solution were replaced by an equal weight of styrene. ${ }^{7}$ Prior to each experiment, 0.4 percent of benzoyl peroxide, 0.04 percent of promoter $\mathrm{A}$, and 0.15 percent of cobalt catalyst were added to the other ingredients to start the polymerization, and the viscous solution was poured into the cylindrical

This material is a 10-percent solution of $\beta$-hydroxy ethyl tetrahydroquinoline in hydrogenated terphenyl and is covered in a pending patent application by Max M. Lee.

6 A casting resin made from a reaction mixture of this composition has been developed at NBS and termed AN-5 casting resin. (M. M. Lee and E. L. Hebb, unpublished experiments.)

7 It was later found that aging of the stock solution may have had a slight effect on the experimental results. A fresh solution, and one which had stood at room temperature for several months, underwent electrical changes during polymerization in satisfactory agreement with one another, as far as the magnitudes of the tion in satisfactory agreement with one another, as far as the magnitudes of the
electrical variables were concerned. However, the plots of these variables as a function of time were somewhat displaced toward shorter times in the case of the function of time were somewhat displaced toward shorter times in the case of the old solution, presumably because of a small amount of progressive polymerization.
This variation is of no importance, as far as most of the experimental results presented in section 3 are concerned, because we shall not be concerned with kinetic questions, for the most part. In the one case where a qualitative examinaof kinetic factors was made (effect of peroxide concentration) care was taken to perform all the runs less than 1 month apart and to keep the stock solution under refrigeration. sample holder, which was kept at $50^{\circ} \pm 0.5^{\circ} \mathrm{C}$ by circulating water from a thermostat through its jacket. The samples were kept at $50^{\circ} \mathrm{C}$ for about $35 \mathrm{hr}$ and were subsequently cured for $14 \mathrm{hr}$ at $100^{\circ}$ C. The $50^{\circ}$ cure, during which the electrical measurements were carried out, took place in a room in which the humidity was controlled to not exceed 50 percent, and the sample holder was kept stoppered during that period.

Also, to make possible a determination of the dielectric properties of the fully polymerized resin as a function of temperature, the polymerizing mixtures were poured into forms somewhat larger than the required samples and were cured in a desiccator at the same temperatures and for the same lengths of time as the samples investigated during their polymerization.

Measurements of dielectric constant and dielectric loss were made throughout the polymerization in two two-terminal sample holders designed for liquids and consisting of stainless-steel concentric cylinders separated by a 1/8-in. gap. These sample holders were calibrated with benzene. Their interelectrode and residual capacitances were approximately 7 and $2 \mu \mu \mathrm{f}$, respectively. Although this equipment should be inherently capable of dielectric-constant determinations accurate to several tenths of 1 percent, some of the measurements probably resulted in values that were as much as 5 percent low, as discussed later. Loss tangents could be determined with an accuracy of $\pm 3 \times 10^{-4}$, resulting in lossfactor accuracies of $\pm 9 \times 10^{-4}$ at a dielectric constant of 3.0. The same variables, as well as the d-c conductivity, were also measured as a function of temperature for the fully cured samples prepared in disk form. These measurements were made on a hightemperature two-terminal sample holder for solids housed in an air thermostat [6]. The estimated accuracy of the dielectric-constant determination on this sample holder is believed to be within 1 percent; that of the loss tangent was $\pm 2 \times 10^{-4}$, resulting in loss-factor accuracies of $\pm 6 \times 10^{-4}$ at a dielectric constant of 3.0. The d-c conductivity measurements were made with the help of a d-c micromicroampere amplifier connected directly to the high-temperature sample holder, capable of measuring currents of $2 \times 10^{-11} \mathrm{amp}$. The samples prepared for these measurements had been machined to give disks $1 \frac{1}{2}$ in. in diameter and $3 / 16$ in. thick, with surfaces flat and parallel within 0.0005 in. Secondary electrodes had been applied to these samples by spraying them with a commercial silver paint.

All measurements of dielectric constant and loss were carried out on the same model of a commercial a-c bridge. Two different bridges, but of the same make, were used with the cylindrical and the hightemperature sample holders, which, because of a replacement of a capacitor in one of them, gave capacitance readings of different accuracies, i. e., to \pm 0.005 and $\pm 0.001 \mu \mu f$, respectively. The signal was generated by a beat frequency oscillator, capable of a 10-v rms output. For detection of the signal a preamplifier and a cathode-ray oscilloscope 
were used in conjunction with the cylindrical sample holder and a preamplifier with a null-detector in conjunction with the high-temperature sample holder.

Nitrogen analyses were performed by a microKjeldahl method. These gave the acrylonitrile concentration in the cured polymer. Separate analyses were performed for each sample investigated in the cylindrical sample holder, because small differences in acrylonitrile content were to be expected due to evaporation during handling and during the polymerization. In the case of the specimens prepared for the high-temperature sample holder, only 1 sample with a nominal acrylonitrile content of 5 percent and 1 of 10 percent were analyzed, because all these samples were cured in 1 batch and in the same desiccator, and because differences in acrylonitrile content between them may be assumed to result only from differences in acrylonitrile content in the polymerizing mixture, which can be calculated from the percentage composition.

\section{Results and Discussion}

\subsection{Electrical Behavior During the Polymerization Process}

Figure 1 illustrates the electrical behavior of a typical polymerizing mixture as a function of time at several frequencies. The initial loss factor, especially at the lower frequencies, was very high and decreased rapidly with time. The frequency dependence of these initially high losses suggested the presence of considerable d-c conductivity, and this was borne out in a d-c conductivity measurement of a sample of acrylonitrile, which gave a value of approximately $2.5 \times 10^{-7} \mathrm{mho} / \mathrm{cm}$. This conductivity was much too high to be attributable to the acrylonitrile itself, and could be reduced roughly by a factor of 50 if a careful fractional distillation process was carried out. This was not done in the experiments cited because the a-c losses attributable to the d-c conductivity decreased rapidly with time and vanished in the fully cured resin. The small amount of cobalt catalyst in the polymerizing mixture, because of its ionic nature, also contributed to the previously noted upswing of the loss curves toward the zero time axis. After these ionic losses had substantially disappeared, a second rise took place in the loss factor at all frequencies, accompanied by a decrease in the dielectric constant. This loss appeared and went through its maximum, first at the highest frequency and last at the lowest frequency, and is attributed to dipole orientation associated with a relaxation time, $\tau$. The loss factor must therefore go through a maximum at a frequency $f_{\max }$ given by eq (1). In terms of the qualitative hydrodynamic concept, the "internal viscosity", and therefore the relaxation time, will increase with the extent of the reaction. This explains the observed shift of the loss maximum from high to low frequencies as the polymerization procedes. The gel point occurs shortly after the $70,000-\mathrm{c} / \mathrm{s}$ loss factor starts on its pronounced rise. The loss factor shows no discon-
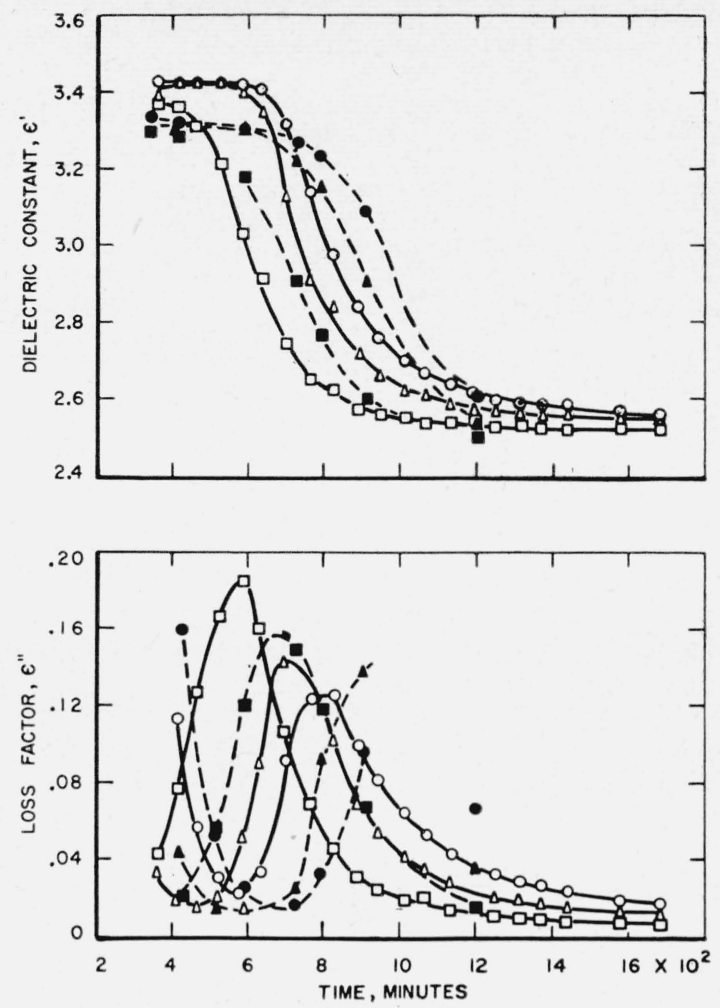

Figure 1. Dielectric constant and loss factor at $50^{\circ} \mathrm{C}$ as a function of time after initiation of polymerization for a sample containing 4.9 percent of $A N$ and 2 percent of $D V B$ solution.

$0,100 \mathrm{c} / \mathrm{s} ; \triangle, 1,000 \mathrm{c} / \mathrm{s} ; \square, 70,000 \mathrm{c} / \mathrm{s}$. Filled in symbols and dashed curves refer to an alternate run made with a polymerizing mixture of the same nominal composition for which an AN analysis was not available.

tinuity at the gel point. The curves of figure 1 bear a superficial resemblance to the Debye dispersion curves modified for a distribution of relaxation times $[7,8,9]$ if the time axis is imagined replaced by a log frequency axis. This results from the fact that the rate of change of dielectric constant with time must be correlated with the magnitude of the out-ofphase component of the complex dielectric constant, i. e., the loss factor. Figure 1 also presents points from another run made with a fresher stock solution. The reproducibility is satisfactory as far as the shape of the curves is concerned; their displacement with respect to one another is probably caused by some progressive polymerization in the older solution, as discussed in section 2. A slight variation in the acrylonitrile content of the two samples may also have contributed to the shift.

To a first approximation, the magnitudes of the loss-factor maxima at any frequency are proportional to the concentration of acrylonitrile at a DVB concentration of 2 percent (table 1). The loss is therefore attributed primarily ${ }^{8}$ to the orien-

${ }^{8}$ E. B. Baker, R. P. Auty, and G. J. Ritenour, J. Chem. Phys. 21, 159 (1953) have shown that polystyrene itself exhibits dipolar losses, which presumably inseparable from the one described, but amounts to only a small fraction of it. 
TABLE 1. Magnitude of loss-factor maxima during polymerization at $50^{\circ} \mathrm{C}$ for various concentrations of $A N$ and of $D V B$ solution.

\begin{tabular}{|c|c|c|c|c|c|c|}
\hline \multirow{2}{*}{$\begin{array}{l}\text { Concen- } \\
\text { tration } \\
\text { of DVB } \\
\text { solution }\end{array}$} & \multirow{2}{*}{$\begin{array}{c}\text { Concen- } \\
\text { tration } \\
\text { of AN }\end{array}$} & \multicolumn{5}{|c|}{ Loss-factor maximum at- } \\
\hline & & $100 \mathrm{c} / \mathrm{s}$ & $300 \mathrm{c} / \mathrm{s}$ & $1,000 \mathrm{c} / \mathrm{s}$ & $10,000 \mathrm{c} / \mathrm{s}$ & $70,000 \mathrm{c} / \mathrm{s}$ \\
\hline $\begin{array}{c}w t \% \\
0 \\
2 \\
2 \\
6 \\
11\end{array}$ & $\begin{array}{r}w t \% \\
5.7 \\
4.9 \\
10.9 \\
4.4 \\
4.2\end{array}$ & $\begin{array}{r}0.125 \\
.125 \\
.257 \\
.094 \\
.052\end{array}$ & $\begin{array}{l}0.133 \\
.296 \\
.104 \\
.060\end{array}$ & $\begin{array}{r}0.185 \\
.142 \\
.287 \\
.107 \\
.059\end{array}$ & $\begin{array}{r}0.211 \\
.188 \\
.328 \\
.122 \\
.070\end{array}$ & $\begin{array}{r}0.230 \\
.186 \\
.335 \\
.137 \\
.085\end{array}$ \\
\hline
\end{tabular}

tation of the $\mathrm{CN}$ dipoles. A similar dependence of the magnitudes of the loss-factor maxima on the acrylonitrile concentration is found for the hightemperature measurements made on the fully cured polymer discussed later (figs. 4 and 7 , table 5).

The peak losses at any frequency decrease as the concentration of cross-linking agent is increased (table 1). A plot of loss factor versus log frequency for various concentrations of DVB shows the maxima to decrease and the curves to become broader as the concentration of DVB is increased (fig. 2). ${ }^{9}$ These phenomena can best be described in terms of a broadened distribution of relaxation times resulting from an increasing failure of the $\mathrm{CN}$ dipoles to orient independently of one another. This effect is seen to be most pronounced at the highest DVB concentrations.

Table 2 shows the time at which they $70,000-\mathrm{c} / \mathrm{s}$ loss peak occurs for various peroxide concentrations. Qualitative observations of the fluidity of the solution and, later, of the rigidity of the gel as a function of time indicated that the polymerization rate was strongly dependent on the peroxide concentration at concentrations below 0.2 percent, but that no such dependence could be readily observed in the range

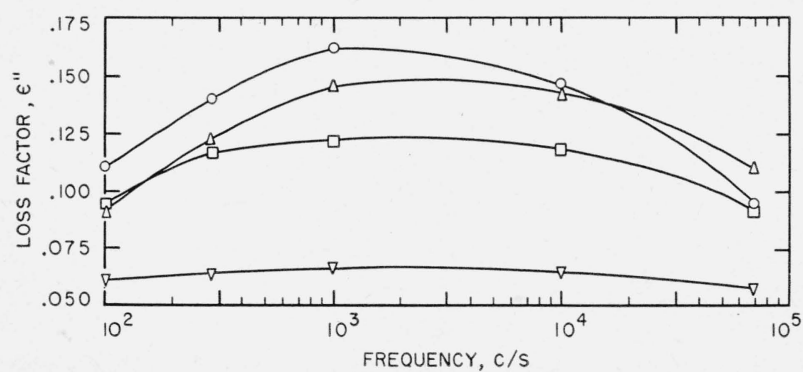

Figure 2. Loss factor during polymerization at $50^{\circ} \mathrm{C}$ as a function of frequency at the approximate time at which the 1,000-c/s loss-factor maximum occurs for several concentrations of the DVB solution.

Loss-factor values have been corrected to an AN content of 5.0 percent. 0 , 0 -percent DVB solution. $\triangle$, 2-percent DVB solution. $\square, 6$-percent DVB, solution. $\nabla, 11$-percent DVB solution.

\footnotetext{
${ }^{9}$ In order to make this comparison more significant, the data plotted in this
figure have been corrected to the same AN concentration. This is done by figure have been corrected to the same AN concentration. This is done by
making use of the fact that any linear theory of polarization requires proportionality between dipole concentration and dielectric loss at any frequency, subject to the restriction that the distribution of relaxation times is independent of dipole concentration.
}

TABLE 2. Time for $70,000-c / s$ loss factor to reach its maximum as a function of the peroxide concentration; polymerization carried out at $50^{\circ} \mathrm{C}$

Concentrations of $\mathrm{AN}$ and of DVB solution are 4.9 and 2 percent, respectively

\begin{tabular}{|c|c|}
\hline $\begin{array}{c}\text { Peroxide } \\
\text { concen- } \\
\text { tration }\end{array}$ & Time \\
\hline wt. $\%$ & $\min$ \\
0.1 & $>4080$ \\
.2 & 730 \\
.4 & 645 \\
\hline
\end{tabular}

TABLE 3. Effect of an additional 60-hour cure at $100^{\circ} \mathrm{C}$ on the electrical properties at $24^{\circ} C$ of a sample containing 4.9 percent of $A N$ and 2 percent of $D V B$ solution

\begin{tabular}{|c|c|c|c|c|}
\hline \multirow{2}{*}{$\begin{array}{c}\text { Fre- } \\
\text { quency }\end{array}$} & \multicolumn{2}{|c|}{ Standard cure } & \multicolumn{2}{|c|}{ Prolonged cure } \\
\hline & $\begin{array}{l}\text { Dielectric } \\
\text { constant }\end{array}$ & $\begin{array}{c}\text { Loss } \\
\text { factor }\end{array}$ & $\begin{array}{l}\text { Dielectric } \\
\text { constant }\end{array}$ & $\begin{array}{l}\text { Loss } \\
\text { factor }\end{array}$ \\
\hline$c / s$ & & & & \\
\hline $\begin{array}{l}100 \\
300\end{array}$ & $\begin{array}{l}2.54 \\
2.54\end{array}$ & $\begin{array}{l}0.0026 \\
0030\end{array}$ & 2. 52 & 0.0020 \\
\hline 1,000 & 2.54 & .0030 & 2.51 & .0018 \\
\hline 10,000 & 2. 53 & .0028 & 2. 51 & .0028 \\
\hline 70,000 & 2. 53 & .0016 & 2. 51 & .0020 \\
\hline
\end{tabular}

from 0.2 to 0.4 percent. This indicates that the time at which the loss peak occurs at any one frequency, under conditions where the structure of the polymer and the reaction mechanism may be assumed to be identical, is a convenient measure of the reaction rate.

After approximately $35 \mathrm{hr}$ at $50^{\circ} \mathrm{C}$, followed by a 14-hr cure at $100^{\circ} \mathrm{C}$, this being the standard cure condition, the dielectric constant and loss at all frequencies had become essentially constant. Table 3 shows the effect of an additional $60-\mathrm{hr}$ cure at $100^{\circ} \mathrm{C}$. There is no significant change in the values of the loss factor during that period. The new values of the dielectric constant are slightly lower, but this is probably caused by shrinkage of the sample. The conclusion seems warranted that the electrical properties of the sample did not change significantly after the initial cure. This conclusion is not surprising, as, in terms of the qualitative picture presented here, a nonpolar plasticizer and small amounts of unpolymerized monomer would be expected to affect the electrical properties in a similar manner, i. e., primarily by reducing the "internal viscosity." It has been shown by Fuoss [10] that the effect of the plasticizer is most pronounced at very low concentrations. In the presence of relatively high plasticizer concentrations (13 percent in this case) small amounts of unpolymerized monomer should therefore have no significant effect on the electrical properties, which, in systems like the one discussed here, should notbe expected to provide a sensitive criterion for completeness of cure.

Table 4 provides data comparing the properties of a sample cured as described and measured in the cylindrical cell for liquids with the average computed 
TABLE 4. Comparison of electrical properties of two samples of identical composition, cured in cylindrical cell and disk form, respectively

\begin{tabular}{|c|c|c|c|c|c|}
\hline \multicolumn{3}{|c|}{ Sample $A^{1}$} & \multicolumn{3}{|c|}{ Sample B 2} \\
\hline \multicolumn{6}{|c|}{$24^{\circ} \mathrm{C}$} \\
\hline Frequency & $\begin{array}{l}\text { Dielec- } \\
\text { tric con- } \\
\text { stant }\end{array}$ & $\begin{array}{l}\text { Loss } \\
\text { factor }\end{array}$ & $\begin{array}{l}\text { Frequen- } \\
\text { cy }\end{array}$ & $\begin{array}{l}\text { Dielec- } \\
\text { tric con- } \\
\text { stant }\end{array}$ & $\begin{array}{l}\text { Loss } \\
\text { factor }\end{array}$ \\
\hline $\begin{array}{c}c / s \\
100 \\
1,000 \\
10,000 \\
70,000\end{array}$ & $\begin{array}{l}2.54 \\
2.54 \\
2.53 \\
2.53\end{array}$ & $\begin{array}{r}0.0026 \\
.0030 \\
.0028 \\
.0016\end{array}$ & $\begin{array}{r}c / s \\
100 \\
1,000 \\
10,000 \\
100,000\end{array}$ & $\begin{array}{l}2.65 \\
2.64 \\
2.64 \\
2.63\end{array}$ & $\begin{array}{r}0.0062 \\
.0038 \\
.0041 \\
.0038\end{array}$ \\
\hline \multicolumn{6}{|c|}{$80^{\circ} \mathrm{C}$} \\
\hline $\begin{array}{r}100 \\
1,000 \\
10,000 \\
70,000\end{array}$ & $\begin{array}{l}2.80 \\
2.67 \\
2.60 \\
2.58\end{array}$ & $\begin{array}{r}0.105 \\
.078 \\
.032 \\
.019\end{array}$ & $\begin{array}{r}100 \\
1,000 \\
10,000 \\
100,000\end{array}$ & $\begin{array}{l}2.83 \\
2.73 \\
2.64 \\
2.59\end{array}$ & $\begin{array}{r}0.089 \\
.055 \\
.033 \\
.025\end{array}$ \\
\hline
\end{tabular}

1 Cured in the cylindrical cell. (Same sample used in table 3.)

${ }^{2}$ Average computed from 2 samples cast and cured in disk form and measured on the high-temperature holder. The AN concentration of this sample was reduced to that of sample $\mathrm{A}$.

for two fully-cured disks of identical composition (complete data are presented in fig. 4) measured on a high-temperature sample holder. Data for this comparison had been made available by taking several of the samples polymerized in the cylinderical cell through part of the temperature range covered by the high-temperature sample holder and by interpolating (fig. 4) from values obtained on that sample holder to make the comparison at $80^{\circ} \mathrm{C}$. In accounting for discrepancies between the two sets of values, the following factors should be kept in mind: Shrinkage of the sample during polymerization in the cylinderical cell, curing conditions that could not be made exactly identical (e. g., different surface areas and different rates of evaporation), different geometries and different electrical arrangements of the sample holders, and different rates of attainment of temperature equilibrium throughout electrodes and sample. Shrinkage during polymerization probably accounts for the lower dielectricconstant values obtained in the cylinderical cell. Surface conductance at the lower frequencies, and a small effective series resistance due to the secondary silver electrodes at the higher frequencies, together with the difference in curing conditions could account for the somewhat higher loss-factor values obtained on the high-temperature sample holder at room temperature. The discrepancies between the lossfactor values obtained at $80^{\circ} \mathrm{C}$ are probably due to imperfect temperature equilibrium, because in this region the loss factor changes rapidly with temperature. The most rapid change takes place at precisely the frequency $(1,000 \mathrm{c} / \mathrm{s})$ at which the discrepancy is largest. In view of these considerations, one may conclude that the samples prepared by the two methods were closely similar in their electrical response. It should be kept in mind that studies of dielectric properties as a function of temperature are as yet relatively rare and that questions of the reproducibility of such measurements at elevated temperatures, even when carried out on the same sample holder, have been left virtually unexplored.

\subsection{Electrical Behavior of the Fully Cured Resin}

When the electrical properties of the fully cured resin are investigated as a function of temperature, a familiar behavior is found [5]. At any frequency there is a sharp rise in dielectric constant with temperature, a maximum is reached, followed by a slow decrease. Paralleling this, there is a rise in loss factor, a maximum occurs, and by the time the dielectric constant has gone through a maximum, the loss factor is small again. It is also a familiar fact that the rise in dielectric constant and loss factor shifts to higher temperatures as the frequency is raised. This is consistent with eq (1) and the qualitative hydrodynamic concept, which predicts a decrease of the relaxation time with temperature, keeping in mind that $\tau$ represents an average value introduced because we are dealing with a distribution of relaxation times. The behavior described is illustrated in figures $3,4,5,6$, and 7 . Figure 4
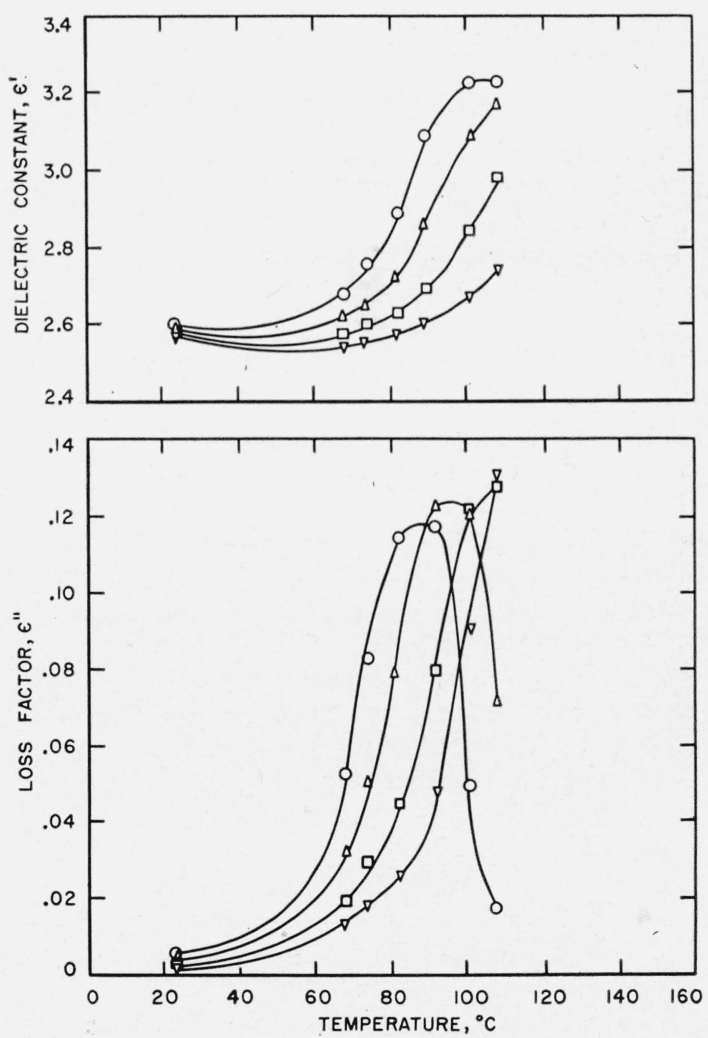

Figure 3. Dielectric constant and loss factor of the fully cured resin as a function of temperature for a sample containing 0 percent of the $D V B$ solution.

AN content is 5.6 percent. $\bigcirc, 100 \mathrm{c} / \mathrm{s}, \triangle, 1,000 \mathrm{c} / \mathrm{s} ; \square, 10,000 \mathrm{c} / \mathrm{s} ; \nabla, 100,000 \mathrm{c} / \mathrm{s}$. 

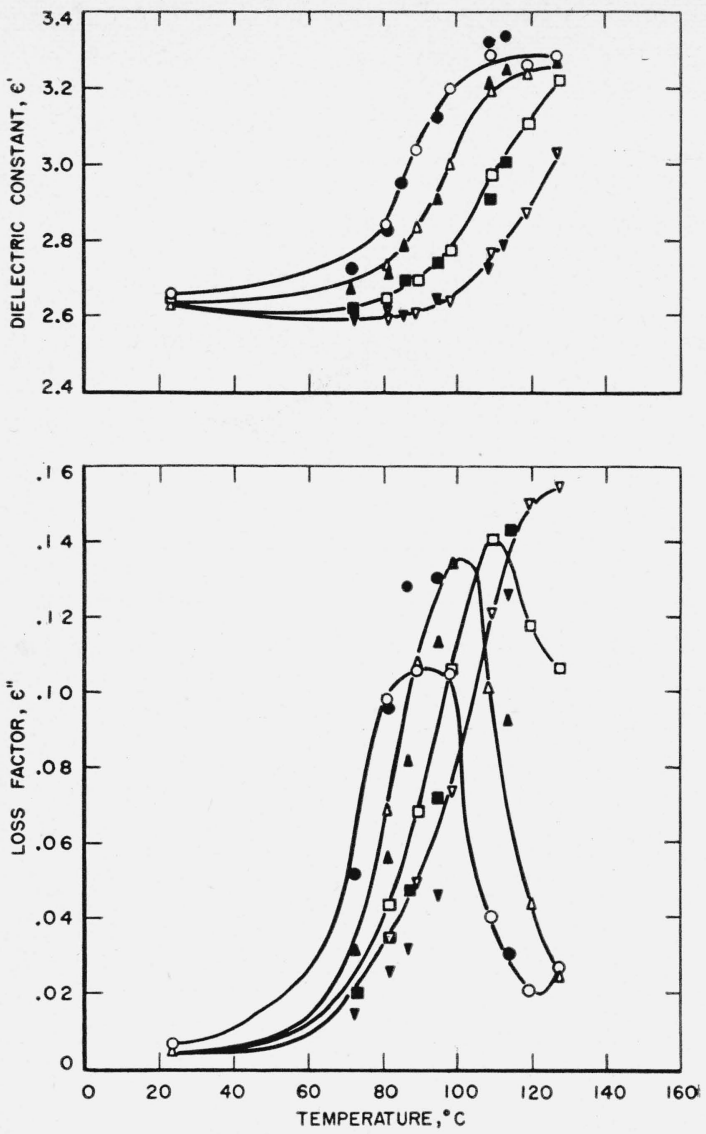

FIgURE 4. Dielectric constant and loss factor of the fully cured resin as a function of temperature for a sample containing 2 percent of the DVB solution.

AN content is 5.6 percent. $\bigcirc, 100 \mathrm{c} / \mathrm{s} ; \Delta, 1,000 \mathrm{c} / \mathrm{s} ; \square, 10,000 \mathrm{c} / \mathrm{s} ; \nabla, 100,000 \mathrm{c} / \mathrm{s}$. Filled in symbols refer to an alternate sample.

includes points from a duplicate run. As the 2 samples from which the 2 runs were made were prepared under identical conditions, the discrepancies between them are probably largely attributable to imperfect temperature equilibrium. The initial small decrease in dielectric constant at the higher frequencies would appear to indicate that in this region the disordering effect of temperature overshadows the dipole alinement.

Figure 8 shows the loss factors as a function of frequency for several concentrations of DVB at approximately the temperature at which the 1,000-c/s loss factors go through their maxima. We note here a parallel with the behavior of the resins during their polymerization at the times at which the $1,000-\mathrm{c} / \mathrm{s}$ loss factors go through their maxima in those systems (fig. 2). In both cases we find that the losses generally become less and the loss factor versus log frequency curves become broader as the concentration of DVB is increased. The interpretation in both cases is the same, although for the fully cured polymer the effect only becomes definitely established at the highest concentrations of DVB. We also note that the magnitudes of the losses in both
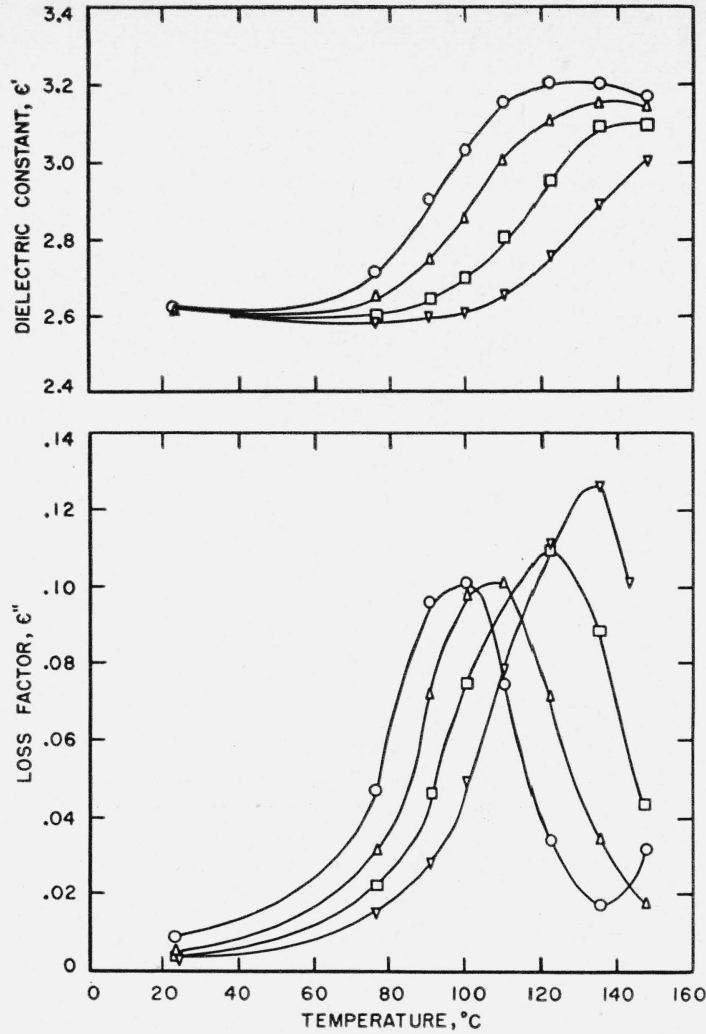

FiguRE 5. Dielectric constant and loss factor of the fully cured resin as a function of temperature for a sample containing 6 percent of the DVB solution.

AN content is 5.3 percent. $\bigcirc, 100 \mathrm{c} / \mathrm{s} ; \triangle, 1,000 \mathrm{c} / \mathrm{s} ; \square, 10,000 \mathrm{c} / \mathrm{s} ; \nabla, 100,000 \mathrm{c} / \mathrm{s}$.

cases are similar. This can be seen best by comparing the loss maxima for each DVB concentration and for each frequency, that is, by picking the proper time for the polymerization studies and the proper temperature for the high-temperature studies on the fully cured polymers (table 5). This observation can be rationalized by the supposition that the losses depend essentially on the average dipole relaxation time, that changes in this relaxation time can be brought about by variation of temperature or by changes in the "internal viscosity" occurring during the polymerization at constant temperature, and that the distribution of relaxation times is not greatly different in the systems compared. Because average molecular weights and molecular-weight distributions during and after complete polymerization are different, this would also mean that the relaxation distribution function is essentially independent of these variables throughout the range considered. It is worth noting that these systems of equivalent electrical response are rather different in their macroscopic mechanical appearance-the polymerizing systems can be described best as gels, the fully polymerized systems as rubbers.

The temperature of the loss-factor maximum at any frequency increases with the concentration of DVB. This is related to the observation that the 

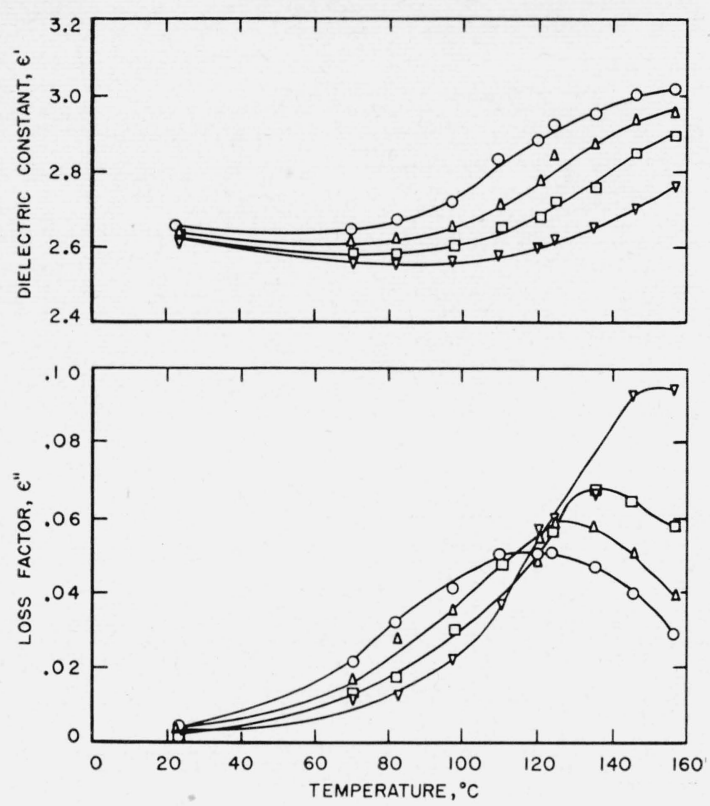

FIGURE 6. Dielectric constant and loss factor of the fully cured

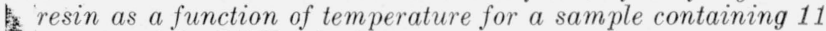
percent of the DVB solution.

$\mathrm{AN}$ content is 5.1 percent. $\bigcirc, 100 \mathrm{c} / \mathrm{s} ; \triangle, 1,000 \mathrm{c} / \mathrm{s} ; \square, 10,000 \mathrm{c} / \mathrm{s} ; \nabla, 100,000 \mathrm{c} / \mathrm{s}$.
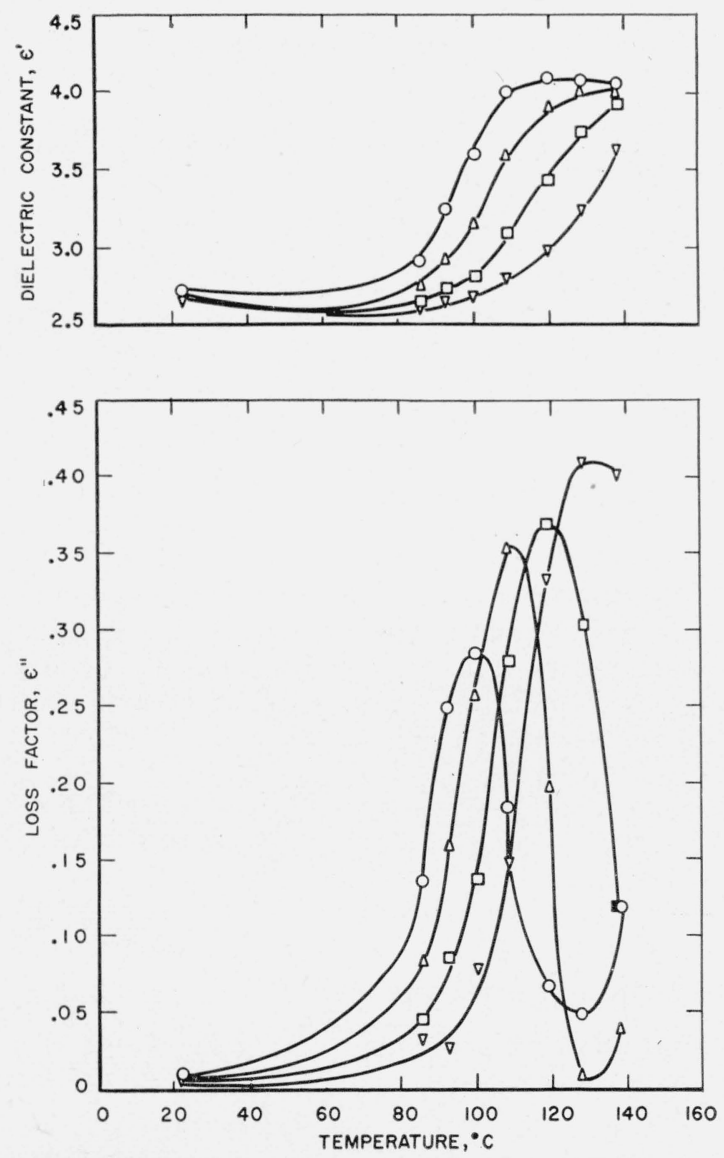

Figure 7. Dielectric constant and loss factor of the fully cured resin as a function of temperature for a sample containing 2 percent of the DVB solution.

AN content is 11.6 percent. $\bigcirc, 100 \mathrm{c} / \mathrm{s} ; \triangle, 1,000 \mathrm{c} / \mathrm{s} ; \square, 10,000 \mathrm{c} / \mathrm{s} ; \nabla, 100,000 \mathrm{c} / \mathrm{s}$.

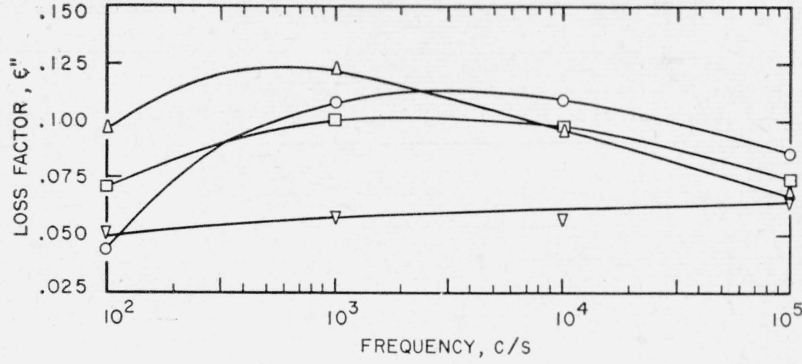

FiguRe 8. Loss factor of the fully cured resin as a function of frequency at the approximate temperature at which the 1,000c/s loss-factor maximum occurs for several concentrations of the DVB solution.

Loss factor values are corrected to an AN content of 5.0 percent. 0 , 0 -percent DVB solution; $\triangle$, 2-percent DVB solution; $\square, 6$-percent DVB solution; $\nabla$, 11-percent DVB solution.

TABLE 5. Comparison of loss-factor maxima reduced to $A N$ contents of 5 or 10 percent of polymerizing systems at $50^{\circ} \mathrm{C}$ and of fully polymerized systems at elevated temperatures

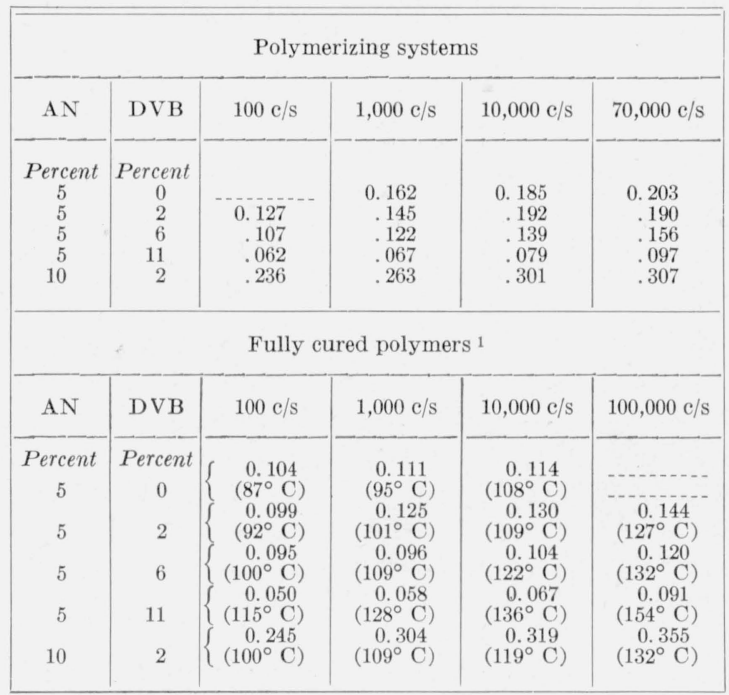

These data were obtained by interpolation from figures $3,4,5,6$, and 7 .

loss maxima occur in the temperature range in which the samples undergo the change from glass-like to rubber-like behavior [11, 12], and that this transition occurs at higher temperatures the higher the concentration of DVB.

At the higher temperatures the samples exhibit some d-c conductivity (table 6), which could be due to a small amount of pyrolysis or to a freeing of ionic impurities in the polymerizing mixture. Ionic conductance in phase with the applied field gives rise to an equivalent a-c loss factor equal to $18 \times 10^{11}$ $G / f$, where $G$ is the d-c conductivity. When this quantity is subtracted from the measured a-c loss factor, the remainder should be representative of the dipolar loss alone. A calculation shows that after this subtraction is made, the a-c loss factor still increases with temperature, after having gone through a minimum, and, although this may mean that a second dipolar loss mechanism has come into play, an alternate explanation is that the ionic 
TABLE 6. Direct-current conductivities of fully cured resins as a function of temperature

\begin{tabular}{|c|c|c|c|c|c|c|c|c|c|}
\hline \multicolumn{2}{|c|}{$\begin{array}{l}0 \text { percent of DVB solu- } \\
\text { tion, } 5.6 \text { percent of } \mathrm{AN}\end{array}$} & \multicolumn{2}{|c|}{$\begin{array}{l}2 \text { percent of } \mathrm{DVB} \text { solu- } \\
\text { tion, } 5.4 \text { percent of } \mathrm{AN}\end{array}$} & \multicolumn{2}{|c|}{$\begin{array}{l}6 \text { percent of DVB solu- } \\
\text { tion, } 5.3 \text { percent of } A N\end{array}$} & \multicolumn{2}{|c|}{$\begin{array}{l}11 \text { percent of DVB solu- } \\
\text { tion, } 5.1 \text { percent of } \mathrm{AN}\end{array}$} & \multicolumn{2}{|c|}{$\begin{array}{l}2 \text { percent of DVB solu- } \\
\text { tion, } 11.6 \text { percent of AN }\end{array}$} \\
\hline Temp & $\begin{array}{l}\text { d-c con- } \\
\text { ductivity }\end{array}$ & Temp & $\begin{array}{l}\text { d-c con- } \\
\text { ductivity }\end{array}$ & Temp & $\begin{array}{l}\text { d-c con- } \\
\text { ductivity }\end{array}$ & Temp & $\begin{array}{l}\text { d-c con- } \\
\text { ductivity }\end{array}$ & Temp & $\begin{array}{l}\text { d-c con- } \\
\text { ductivity }\end{array}$ \\
\hline $\begin{array}{c}{ }^{\circ} C \\
23 \text { to } 108 \\
-1 .\end{array}$ & $\begin{array}{c}\text { Mho/cm } \\
<5 \times 10^{-15}\end{array}$ & $\begin{array}{c}{ }^{\circ} C \\
23 \text { to } 98 \\
109 \\
119 \\
127 \\
-\end{array}$ & $\begin{array}{c}\text { Mho/cm } \\
<5 \times 10^{-15} \\
2 \times 10^{-14} \\
6 \times 10^{-14} \\
15 \times 10^{-14} \\
-\end{array}$ & $\begin{array}{c}{ }^{\circ} C \\
23 \text { to } 110 \\
122 \\
135 \\
-\end{array}$ & $\begin{array}{c}\text { Mho/cm } \\
<5 \times 10^{-15} \\
3 \times 10^{-14} \\
15 \times 10^{-14} \\
- \\
\end{array}$ & $\begin{array}{c}{ }^{\circ} C \\
23 \text { to } 120 \\
124 \\
135 \\
146 \\
157\end{array}$ & $\begin{array}{l}\text { Mho/cm } \\
<5 \times 10^{-15} \\
2 \times 10^{-14} \\
7 \times 10^{-14} \\
20 \times 10^{-14} \\
60 \times 10^{-14}\end{array}$ & $\begin{array}{c}{ }^{\circ} C \\
128 \\
138 \\
-1 .- \\
-1 .\end{array}$ & \begin{tabular}{c} 
Mho/cm \\
$4 \times 10^{-13}$ \\
$13 \times 10^{-13}$ \\
- \\
\hdashline
\end{tabular} \\
\hline
\end{tabular}

conductance has an out-of-phase component, giving a larger a-c loss than that which would be expected from a pure ionic in-phase mechanism [13].

By application of the theory of absolute reaction rates to dielectric relaxation [14], one obtains

$$
1 / \tau=k T / h e^{\Delta S / R} e^{-\Delta H / R T},
$$

where $k$ is the Boltzmann constant, $h$ is Planck's constant, and $\Delta S$ and $\Delta H$ are entropy and heat of activation, respectively. Calculations of $\Delta S$ and $\Delta H$ were performed for all samples for which sufficient data were available (all except the sample containing no crosslinking agent). As an additional check, a run was made with another sample containing 2 percent of the DVB solution, and measurements were made at closer frequency intervals (table 7 ). Figure 9 shows the plots of $\log f_{\max }$ versus $1 / T$ for all these systems made from the data in figures $4,5,6,7$ and table 7 . These plots give, within the experimental error, parallel lines, and the heat of activation averages $63,000 \mathrm{cal} / \mathrm{mole}$. For the entropies of activation, values of 122,115 , and 107 (cal $/ \mathrm{mole}) / \mathrm{deg}$ are obtained for the samples containing 2,6 , and 11 percent of the DVB solution, respectively, and the normal amount of acrylonitrile, whereas a value of 115 (cal $/ \mathrm{mole}) / \mathrm{deg}$ is obtained for the sample with the high AN content. The systems investigated there-

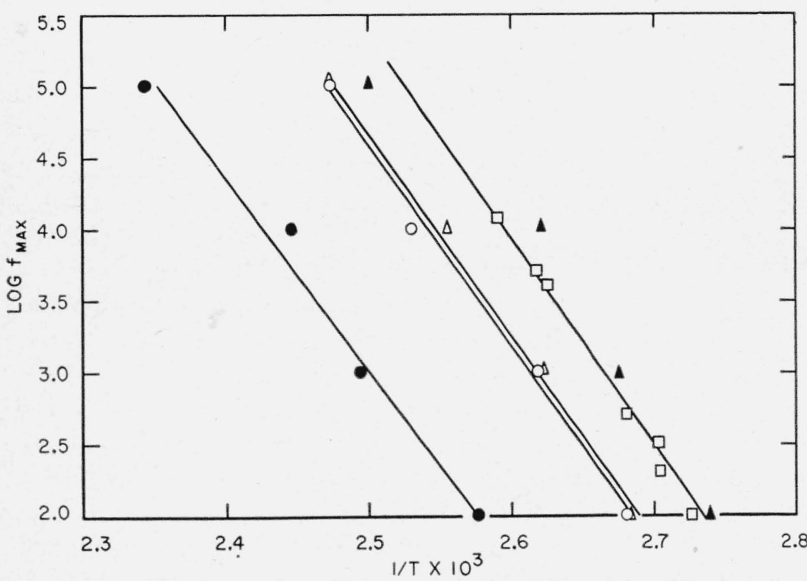

FIGURE 9. Log $f_{\max }$ as a function of reciprocal absolute temperature for the samples whose behavior is illustrated in figures 3 to $\%$.

A, $\square, 2$ different samples with 2-percent DVB solution; $\bigcirc$, 6-percent DVB solution; 9,11 -percent DVB solution; $\boldsymbol{\Lambda}, \square, \bigcirc, \bullet$, approximately 5-percent AN; $\triangle, 2$-percent DVB, 11-percent AN.
TABLE 7. Detailed high-temperature data for a sample containing 5.4 percent of $A N$ and 2 percent of $D V B$ solution

\begin{tabular}{|c|c|c|c|c|c|}
\hline $\begin{array}{c}\text { Fre- } \\
\text { quency }\end{array}$ & $\begin{array}{l}\text { Dielectric } \\
\text { constant }\end{array}$ & $\begin{array}{l}\text { Loss } \\
\text { factor }\end{array}$ & $\begin{array}{c}\text { Fre- } \\
\text { quency }\end{array}$ & $\begin{array}{c}\text { Dielectric } \\
\text { constant }\end{array}$ & $\begin{array}{l}\text { Loss } \\
\text { factor }\end{array}$ \\
\hline \multicolumn{3}{|c|}{$94^{\circ} \mathrm{C}$} & \multicolumn{3}{|c|}{$108^{\circ} \mathrm{C}$} \\
\hline $\begin{array}{c}c / s \\
10^{2} \\
2 \times 10^{2} \\
5 \times 10^{2} \\
10^{3} \\
2 \times 10^{3} \\
5 \times 10^{3} \\
10^{4} \\
2 \times 10^{4} \\
5 \times 10^{4} \\
10^{5}\end{array}$ & $\begin{array}{l}3.053 \\
2.987 \\
2.917 \\
2.827 \\
2.766 \\
2.719 \\
2.667 \\
2.639 \\
2.606 \\
2.573\end{array}$ & $\begin{array}{l}0.131 \\
.133 \\
.131 \\
.115 \\
.0985 \\
.086 \\
.073 \\
.062 \\
.0525 \\
.047\end{array}$ & $\begin{array}{c}c / i \\
10^{2} \\
2 \times 10^{2} \\
5 \times 10^{2} \\
10^{3} \\
2 \times 10^{3} \\
5 \times 10^{3} \\
10^{4} \\
2 \times 10^{4} \\
5 \times 10^{4} \\
10^{5}\end{array}$ & $\begin{array}{l}3.242 \\
3.213 \\
3.171 \\
3.084 \\
3.014 \\
2.927 \\
2.837 \\
2.772 \\
2.708 \\
2.649\end{array}$ & $\begin{array}{l}0.056 \\
.076 \\
.110 \\
.125 \\
.137 \\
.140 \\
.125 \\
.119 \\
.114 \\
.093\end{array}$ \\
\hline \multicolumn{3}{|c|}{$97^{\circ} \mathrm{C}$} & \multicolumn{3}{|c|}{$113^{\circ} \mathrm{C}$} \\
\hline $\begin{array}{r}10^{2} \\
2 \times 10^{2} \\
5 \times 10^{2} \\
10^{3} \\
2 \times 10^{3} \\
5 \times 10^{3} \\
10^{4} \\
2 \times 10^{4} \\
5 \times 10^{4} \\
10^{5}\end{array}$ & $\begin{array}{l}3.105 \\
3.039 \\
2.959 \\
2.867 \\
2.801 \\
2.738 \\
2.677 \\
2.634 \\
2.599 \\
2.564\end{array}$ & $\begin{array}{r}0.125 \\
.134 \\
.142 \\
.132 \\
.119 \\
.104 \\
.089 \\
.074 \\
.064 \\
.055\end{array}$ & $\begin{array}{r}10^{2} \\
2 \times 10^{2} \\
5 \times 10^{2} \\
10^{3} \\
2 \times 10^{3} \\
5 \times 10^{3} \\
10^{4} \\
2 \times 10^{4} \\
5 \times 10^{4} \\
10^{5}\end{array}$ & $\begin{array}{l}3.242 \\
3.237 \\
3.214 \\
3.160 \\
3.108 \\
3.031 \\
2.918 \\
2.861 \\
2.789 \\
2.707\end{array}$ & $\begin{array}{l}0.0308 \\
.0423 \\
.069 \\
.094 \\
.113 \\
.138 \\
.143 \\
.140 \\
.138 \\
.126\end{array}$ \\
\hline
\end{tabular}

fore show the high values of both heat and entropy of activation commonly observed for dipolar relaxation in high polymers [11].

It has been shown that distributions of relaxation times can be calculated from dielectric dispersion $[9,15,16]$ and that dielectric losses can be calculated from dielectric-constant data without introducing any assumptions concerning the form of the distribution function [15]. We have for a linear dielectric of very small d-c conductivity:

$$
\begin{aligned}
\epsilon^{\prime}(\omega)-\epsilon_{\infty} & =\int_{0}^{\infty} \frac{y(\tau) d \tau}{1+\omega^{2} \tau^{2}}=\int_{-\infty}^{+\infty} \frac{Y(\ln \tau) d \ln \tau}{1+\omega^{2} \tau^{2}}, \\
\epsilon^{\prime \prime}(\omega) & =\int_{0}^{\infty} \frac{y(\tau) \omega \tau d \tau}{1+\omega^{2} \tau^{2}}=\int_{-\infty}^{+\infty} \frac{\omega \tau Y(\ln \tau) d \ln \tau}{1+\omega^{2} \tau^{2}} ;
\end{aligned}
$$

and, if the dispersion is not too sharp, we have to a very good approximation [15]:

$$
Y(\ln 1 / \omega)=-\frac{d \epsilon^{\prime}}{d \ln \omega},
$$

where $\mathrm{y}(\tau)$ is the distribution of electrical relaxation 
times ${ }^{10}$ and $Y(\ln \tau) d \ln \tau=y(\tau) d \tau$. Often it is of interest to obtain the function $Y$ from the imaginary part as well. This has been attempted for the analogous mechanical case $[17,18]$. The same treatment applied to the electrical case would result in

$$
Y(\ln 1 / \omega)=-\epsilon^{\prime \prime} \frac{d \log \left(\epsilon^{\prime \prime} / \omega\right)}{d \log \omega} .
$$

As has been pointed out [15], the use of the approximation resulting in (7), when used in the calculation of $\epsilon^{\prime \prime}$ from $\epsilon^{\prime}$, leads to values that are 30 to 40 percent too small. The reason for this discrepancy is that, whereas the approximation made in the calculation of (6), namely,

$$
\frac{1}{1+\omega^{2} \tau^{2}}= \begin{cases}1 & 0<\tau<1 / \omega \\ 0 & 1 / \omega<\tau<\infty\end{cases}
$$

is excellent, the approximation which results in (7), namely,

$$
\frac{\omega \tau}{1+\omega^{2} \tau^{2}}= \begin{cases}\omega \tau & 0<\tau<1 / \omega \\ 0 & 1 / \omega<\tau<\infty\end{cases}
$$

if poor, because we are interested in the integrals of these expressions (fig. 10). It is clear, therefore, that we cannot obtain $Y$ with the aid of approximation (9). We can, however, define a function $Y^{\prime}$, given by

$$
\epsilon^{\prime \prime}=\int_{-\infty}^{\ln 1 / \omega} \omega \tau Y^{\prime}(\ln \tau) d \ln \tau
$$

It is this function $Y^{\prime}$, not $Y$, that is equal to the right-hand side of (7) which must, therefore, be replaced by

$$
Y^{\prime}(\ln 1 / \omega)=-\epsilon^{\prime \prime} \frac{d \log \left(\epsilon^{\prime \prime} / \omega\right)}{d \log \omega} .
$$

We can now calculate $Y^{\prime}$ in terms of $Y$ from eq (5) and (10), obtaining

$$
\int_{-\infty}^{+\infty} \frac{\omega \tau Y(\ln \tau) d \ln \tau}{1+\omega^{2} \tau^{2}}=\int_{-\infty}^{\ln 1 / \omega} \omega \tau Y^{\prime}(\ln \tau) d \ln \tau
$$

Since, in most practical cases, the variation of $Y$ and $Y^{\prime}$ is small in the region in which the integral has a significant value, we can write instead of (12)

$$
Y(\ln \tau) \int_{-\infty}^{+\infty} \frac{\omega \tau}{1+\omega^{2} \tau^{2}} d \ln \tau=Y^{\prime}(\ln \tau) \int_{-\infty}^{\ln 1 / \omega} \omega \tau d \ln \tau
$$

Making use of the symmetry of the integral on the left, and transforming, we obtain

$$
2 Y(\ln \tau) \int_{0}^{1 / \omega} \frac{\omega}{1+\omega^{2} \tau^{2}} d \tau=Y^{\prime}(\ln \tau) \int_{0}^{1 / \omega} \omega d \tau
$$

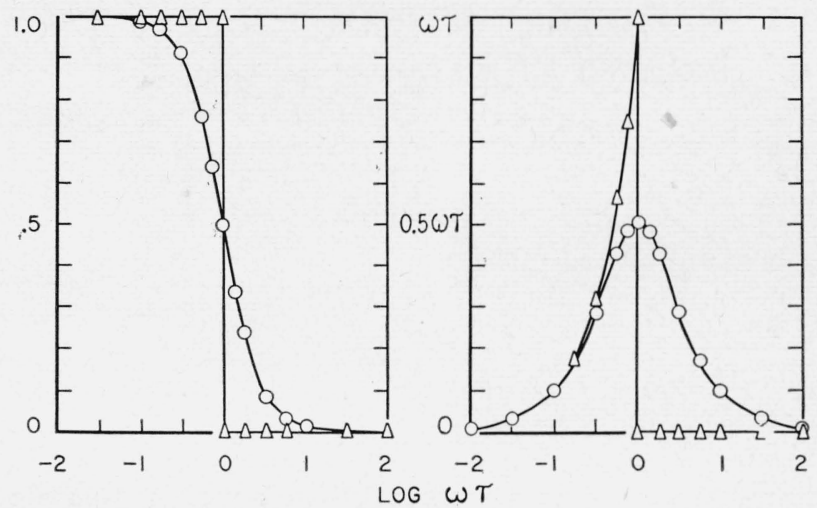

Figure 10. Plot of exact expressions and of approximations required for correlations between real and imaginary parts of the dielectric constant plotted as a function of $\log \omega \tau$.

On the left, $1 /\left(1+\omega^{2} \tau^{2}\right)$ and approximation (8); on the right, $\omega \tau /\left(1+\omega^{2} \tau^{2}\right)$ and approximation (9). $\bigcirc$, exact expressions; $\triangle$, approximations.

Hence

$$
\pi / 2 \quad Y(\ln \tau)=Y^{\prime}(\ln \tau)
$$

i. e., the two functions are simply related through a constant over their entire spectrum, and by (6), (11), and (15)

$$
Y(\ln \tau)=-1 / 2.303 \frac{d \epsilon^{\prime}}{d \log f}=-2 / \pi \epsilon^{\prime} \frac{d \log \epsilon^{\prime \prime} / f}{d \log f} .
$$

The appearance of the factor $2 / \pi$ immediately explains the discrepancy between the observed and calculated values of $\epsilon^{\prime \prime}$ noted previously [15], since the use of approximation (9) is equivalent to the neglect of the difference between $Y$ and $Y^{\prime}{ }^{11}$ For materials whose losses are essentially frequency independent (12) reduces to

$$
Y(\ln \tau)=-1 / 2.303 \frac{d \epsilon^{\prime}}{d \log f}=2 / \pi \epsilon^{\prime \prime} .
$$

The identical relation has been derived by Gevers and Du Pre, using a somewhat different argument [19]. Equation (17) provides a very convenient first approximation connecting dielectric dispersion and loss. Table 8 gives a comparison of values of the loss factor as observed and as calculated by the procedure previously described [15], i. e., through use of eq (6), followed by (5). It also presents values of $Y(\ln \tau)$ calculated from real and imaginary parts of the dielectric constant through the use of eq (16). The reasonable agreement of the two sets of $\epsilon^{\prime \prime}$ and $Y$ values demonstrates the selfconsistency of the approximations outlined, which is fully adequate in view of the inaccuracies entailed by the graphical operations.

For the analogous mechanical case, successful calculations of dynamical properties at various temperatures have been made from measurements at a

11 Ferry et al. [17], who use approximation (9), noted that in some of their results the use of an empirical constant " $a$ " equal to 0.77 occurring in the place of $2 / \pi$ in an equation analogous to (16) harmonized distribution functions calculated from real and imaginary parts of the modulus. 
TABLE 8. Electrical properties of a sample containing 5.4 percent of $A N$ and 2 percent of $D V B$ solution at $94^{\circ} C$

\begin{tabular}{|c|c|c|c|c|c|}
\hline $\begin{array}{c}\text { Fre- } \\
\text { quency }\end{array}$ & $e^{\prime}$ & $\begin{array}{l}\epsilon^{\prime \prime} \text { (ob- } \\
\text { served) }\end{array}$ & $\begin{array}{l}e^{\prime \prime}(\text { cal- } \\
\text { culated) }\end{array}$ & $Y$ (from & $Y$ (from \\
\hline$c / s$ & & & & & \\
\hline $10^{2}$ & 3. 053 & 0.131 & & 0.078 & 0.079 \\
\hline $2 \times 10^{2}$ & 2. 987 & .133 & & .088 & .084 \\
\hline $5 \times 10^{2}$ & 2. 917 & .131 & & .103 & 089 \\
\hline $10^{3}$ & 2. 827 & .115 & 0.124 & .100 & .087 \\
\hline $2 \times 10^{3}$ & 2. 766 & .099 & .109 & .073 & .074 \\
\hline $5 \times 10^{3}$ & 2. 719 & .086 & .092 & .058 & .065 \\
\hline $10^{4}$ & 2. 667 & .073 & .080 & .049 & .055 \\
\hline $2 \times 10^{4}$ & 2. 639 & .062 & & .041 & .047 \\
\hline $5 \times 10^{4}$ & 2. 606 & .0525 & & .039 & .040 \\
\hline $10^{5}$ & 2. 573 & .049 & & .033 & .036 \\
\hline
\end{tabular}

different temperature, using the assumption that the distribution of relaxation times did not change with temperature [20]. Although some success has been reported for the electrical case also [16], similar calculations of $\epsilon^{\prime}$ and $\epsilon^{\prime \prime}$ as a function of temperature, from data obtained at a different temperature, do not give sufficiently accurate results when applied to the data cited here. The reason seems to be that the distribution functions are not independent of temperature. As it is not possible to calculate distribution functions with an accuracy of better than 5 to 10 percent by the method outlined, we may cite the observed increase in the loss-factor maxima at the higher temperatures (table 5) as evidence that these functions sharpen with temperature. Since $\epsilon_{0}-\epsilon_{\infty}$ is proportional to $\int_{-\infty}^{+\infty} \epsilon^{\prime \prime} d \ln f$, and since $\epsilon_{0}$ decreases with temperature while $\epsilon_{\infty}$ is essentially temperature independent over a small temperature range, an increase in the loss-factor maximum with temperature must be connected with a sharpening of the distribution function with temperature. ${ }^{12}$ Such a sharpening has been concluded to occur for polymers in general by several investigators, both on the basis of experimental data and on theoretical grounds $[9,11,12]$.

Because of the analogous effects on the relaxation time of temperature changes in the case of the cured polymer and of "internal viscosity" changes in the case of the growing polymer, it is interesting to note that the loss-factor maxima during the polymerization increase with frequency (table 1).

\section{Summary}

1. The marked changes in dielectric constant and in dielectric loss observed during the polymerization of the polar casting resins described are attributable primarily to the dipolar relaxation of the nitrile groups present.

2. As seen by its electrical effects, the hardening of the reaction mixture at a certain stage of the polymerization is quite similar to the glass-phase transition occurring when the temperature of the fully cured rubber-like polymer is lowered-the

12 This argument assumes that the resultant dipole moment of the polyme molecule is independent of temperature. dipolar relaxations occurring in the above two transitions result in loss factors that agree semiquantitatively, and a similar broadening of the relaxation distribution functions take place upon addition of cross-links in each case.

3 . In the polymerizing systems discussed, electrical measurements can be used as an indicator of reaction rate in a qualitative way. However, such questions as completeness of cure cannot be decided in this manner because all significant electricai changes occur at a relatively early stage of the reaction.

4. A scheme is described whereby distributions of electrical relaxation times can be calculated with comparable accuracy from real and imaginary parts of the complex dielectric constant.

The authors express thanks to Max M. Lee for many helpful suggestions, to Emma Lee Hebb for preparing the polymerizing mixtures, to A. H. Scott for loan of the high-temperature equipment, to M. Wales and L. Williams for performing the molecular weight determination of one of the polystyrenes, to Rolf Paulson for performing the nitrogen analyses, and to A. Glasgow and his group for purifying some of the acrylonitrile.

\section{References}

[1] A. Lazarev and I. Raschketaev, Tech. Phys. USSR 31, 366 (1936).

[2] T. G. Majury and H. W. Melville, Proc. Roy. Soc. [A] 205, 496 (1951).

[3] P. Debye, Polar molecules (Dover Publishers, New York, N. Y.).

[4] J. D. Hoffman and C. P. Smyth, J. Am. Chem. Soc. $7 \boldsymbol{q}$, $171(1950)$

[5] R. M. Fuoss, The chemistry of large molecules, ch. VI (Interscience Publishers, New York, N. Y., 1943). This work lists many references to the original literature.

[6] A. H. Scott and P. Ehrlich, Annual Report of Conference on Electrical Insulation (1953).

[7] K. W. Wagner, Ann. Physik. 40, 817 (1913).

[8] W. A. Yager, Physics 7, 434 (1936)

[9] R. M. Fuoss and J. G. Kirkwood, J. Am. Chem. Soc. 63, 385 (1941)

[10] R. M. Fuoss, J. Am. Chem. Soc. 63, 378 (1941)

[11] W. Kauzmann, Rev. Modern Phys. 14,, 12 (1942).

[12] R. F. Tuckett, Trans. Faraday Soc. 40, 448 (1944).

[13] D. J. Mead and R. M. Fuoss, J. Am. Chem. Soc. 67, $1566(1945)$

[14] S. Glasstone, K. J. Laidler, and H. Eyring, The theory of rate processes, ch. IX (McGraw-Hill Book Co., New York, N. Y., 1941)

[15] P. Ehrlich, J. Research NBS 50, 19 (1953) RP2382.

[16] J. D. Ferry and E. R. Fitzgerald, J. Colloid Sci. 8, 224 (1953).

[17] J. D. Ferry, W. M. Sawyer, G. V. Browning, and A. H. Groth, J. Appl. Phys. 21, 513 (1950).

[18] F. Schwarzl, Physica 17, 923 (1951).

[19] M. Gevers and F. K. Du Pre, Trans. Faraday Soc. 42A $53(1946)$

[20] J. D. Ferry, J. Am. Chem. Soc. 72, 3746 (1950).

Washington, July 23, 1953. 